\title{
Barotropic and Baroclinic Tidal Currents in the Eastern Basins of the North Atlantic
}

\author{
Gerold Siedler and Uwe Paul
}

Institut für Meereskunde an der Universität Kiel, Kiel, Germany

\begin{abstract}
Data from a large-scale moored array in the Iberian and Canary basins are used to determine the energies of barotropic and baroclinic $\mathrm{M}_{2}$ and $\mathrm{S}_{2}$ tides. An analysis of time-varying dynamical modes is performed. The results for barotropic modes confirm the global surface tide model results of Schwiderski (1980) for this region. The barotropic modes dominate in the deep basins, but increased baroclinic contributions are usually found over rough topography. At three locations near the continental slope in the southern Canary Basin the baroclinic modes dominate the barotropic mode. Results from an array of three moorings at the northern part of the Cape Verde Rise show an inverse behavior of barotropic and baroclinic energies, such that the baroclinic energy is steadily enhanced while the barotropic energy is reduced towards the continental margin. The increase in baroclinic energy is consistent with a generation of internal tides close to the shelf by surface tidal forcing over topography. Further evidence for this process is provided by the 2-week periodicity of the first-order baroclinic mode at the slope, corresponding to the spring-neap cycle of the barotropic tide.
\end{abstract}

\section{INTRODUCTION}

Direct current measurements are required for the discrimination of barotropic and baroclinic tides in the open ocean. The large wavelengths and long-wave properties of barotropic tides make it possible to obtain a good approximation of surface elevations from coastal and island tide gauges [e.g., Dietrich, 1944], with data supplemented by a small number of deep-sea tide gauges [Munk and Cartwright, 1966; Cartwright et al., 1980]. The related global surface tide models are well suited to predicting open-ocean tidal properties [Accad and Pekeris, 1978; Schwiderski, 1980] (see also Hendershott [1973]). The distribution of baroclinic tides in the open ocean, however, is more difficult to determine owing to the much smaller horizontal scales, the partition into several vertical modes, and the strong variability of amplitude and phase on time scales of only a few tidal periods [Defant, 1932, 1960; Krauss, 1966; Wunsch, 1975; Roberts, 1975].

In the course of the last 2 decades, long-term current meter time series from moorings have become available at a number of locations, including single moorings [e.g., Schmitz et al., 1988] or coherent arrays [e.g., MODE Group, 1978; Käse and Siedler, 1979]. The summary of Dickson [1989] is a useful source of information on moored observations in the global ocean. Data from deep-sea moorings have been used for tidal studies [Meincke, 1971; Wunsch and Hendry, 1972; Magaard and McKee, 1973; Gould and McKee, 1973; Regal and Wunsch, 1973; Torgrimson and Hickey, 1979; Gordon, 1979; Huthnance, 1981; Huthnance and Baines, 1982; Saunders, 1983; Dick and Siedler, 1985; Weisberg et al., 1987], but sufficient spatial coverage of major ocean basins was lacking.

In the eastern basins of the North Atlantic, current meter time series were obtained by the Institut für Meereskunde (IFM) in Kiel, Germany, from mooring programs with different objectives. These observations together can serve as a large-scale array of stations for a tidal analysis in the Iberian

Copyright 1991 by the American Geophysical Union.

Paper number 91JC02319.

0148-0227/91/91JC-02319\$05.00 and Canary basins (Figure 1). It is the aim of the present study to determine the modal partition of tides at different locations in this large-scale array, to investigate spatial variations in a small-scale coherent array north of the Cape Verde Islands, and to relate the discovered wave properties to earlier observations and model results.

\section{The Data Set}

A typical mooring configuration is shown in Figure 2, and a summary of mooring positions and observational periods is given in Table 1 . The number of current meters per mooring varied between three and eight. The time series obtained are summarized in Figures 3-5. Sampling intervals were 1 or 2 hours. Only data collected by Aanderaa current meters were considered in the present study in order to ensure a consistent data set solely from subsurface moorings. The minimum time series length required for a separation of two distinct semidiurnal $M_{2}$ and $S_{2}$ tides is obtained from the Rayleigh criterion [Godin, 1972]. The frequencies $\sigma_{\mathrm{M}_{2}}$ and $\sigma_{\mathrm{S}_{2}}$ of these two tides have to be separated by at least two elementary frequency bands $\Delta \sigma$ which are determined from the length $T$ of the observational period:

$$
\Delta \sigma=\frac{1}{T}
$$

The condition for resolving $M_{2}$ and $S_{2}$ is then given by

$$
\frac{1}{T}<\frac{1}{2}\left|\sigma_{\mathrm{M}_{2}}-\sigma_{\mathrm{S}_{2}}\right|
$$

or

$$
T>2\left|\frac{1}{12.421}-\frac{1}{12.000}\right|^{-1} \sim 30 \text { days }
$$

This condition is easily fulfilled by the available time series.

Frictional drag will cause a deflection of the mooring line from the vertical, and relative currents will result at the various instrument depth levels. However, tidal periods are sufficiently large compared to the inverted pendulum periods 


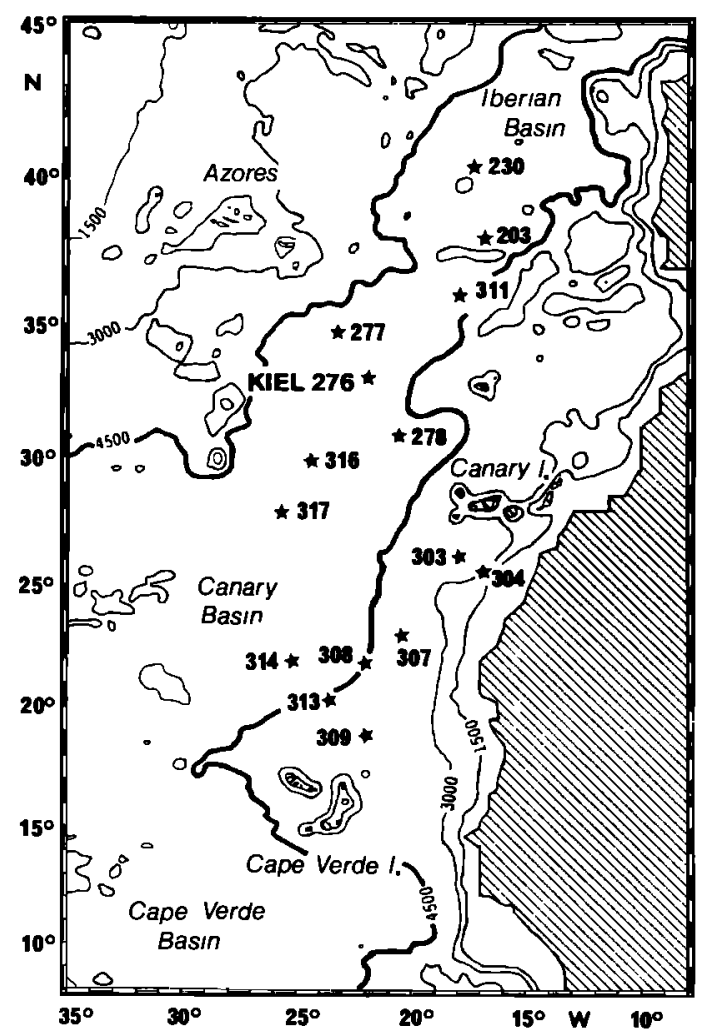

Fig. 1. Positions of moorings in the Iberian and Canary basins. Bottom depth is given in mrters.

of such moorings to warrant the assumption of a steady state rigid pendulum balance for each time step (Figure 6). Relative currents can then be calculated from the instrument displacement per time. The horizontal displacement $\Delta x_{i}$ at level $i$ is deduced from the pressure record at the uppermost instrument, providing the time series of vertical instrument displacement $\Delta d_{o}$ and mooring geometry. With the ratio $L_{i} / L_{o}$ of anchor distances, the displacements at level $i$ and relative currents can then be determined.

As will be shown later, the vertical structure of the flow is dominated by low-order modes. Changes in instrument depth of $O(10 \mathrm{~m})$ or more can therefore be neglected in the analysis. It remains to be checked whether relative currents due to mooring motion can also be neglected. In Figure 7 we present a typical case. The speed record is shown on top, the pressure change time series ( 1 dbar closely corresponding to a depth interval of $1 \mathrm{~m}$ ) in the middle, and the relative speed calculated from the pressure change and mooring geometry on the bottom. Vertical displacements range up to a few decimeters, and relative speeds at tidal frequencies are $O(1 \%)$ of the observed currents. In exceptional cases with "soft" mooring design the relative tidal currents can reach several percent up to about $20 \%$ of the observed tidal currents. Since this strong effect is not typical at all for the whole moored array, we did not consider it necessary to correct for relative currents. Tidal amplitudes obtained from the following analysis can therefore be too small by a few percent due to these effects.

Typical spectra for the east and north components are presented in Figure 8, obtained at mooring KIEL276 (see Figure 1) during the observational period 264-1 (see Table 1). Energetic peaks are found at inertial and semidiurnal peri-

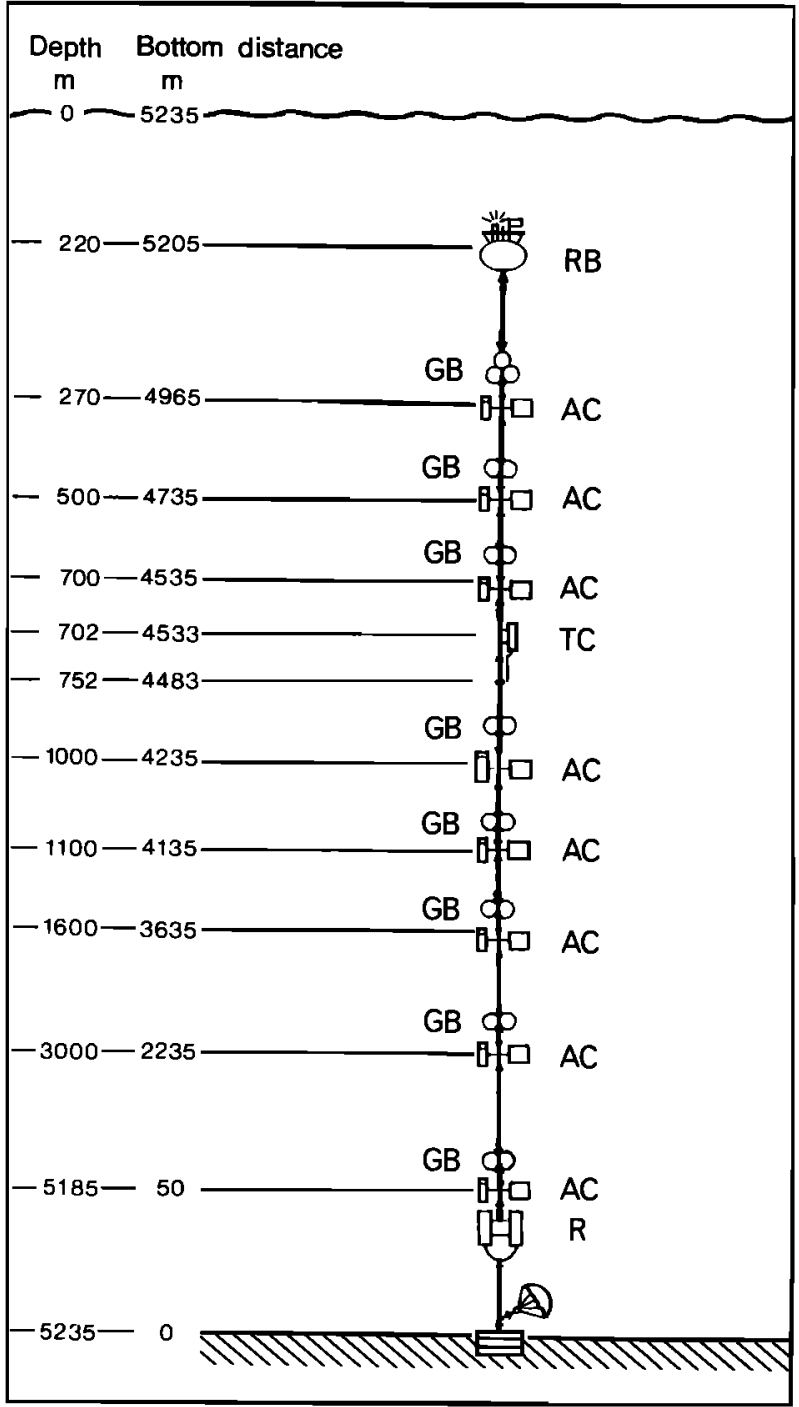

Fig. 2. Schematic typical mooring configuration: RB, radio transmitter buoy; AC, Aanderaa current meter; TC, thermistor chain recorder; $\mathrm{R}$, acoustic release; $\mathrm{GB}$, glass balls.

ods. The band-pass filter response curve is included which is used in the later semidiurnal tidal analysis.

\section{The Ratio of Semidiurnal to Diurnal Tidal AMPLitudes}

The spectral properties in Figure 8 indicate a dominance of semidiurnal versus diurnal tides. We will study this feature in some more detail by performing a Fourier analysis at all instrumented levels for a selected period at KIEL276. The main tidal components (periods in brackets) to be considered are $\mathrm{M}_{2}$ (12.421 hours), $\mathrm{S}_{2}$ (12.000 hours), $\mathrm{K}_{1}$ (23.943 hours), and $\mathrm{O}_{1}$ (25.819 hours).

When performing the Fourier analysis, we assume that the tidal components can be approximated by sinusoidal signals at the above periods with constant amplitude and phase at each depth level during the whole observational period. It is well known that this will be the case only for barotropic tides, while short-term changes of amplitude and phase of internal tides will lead to an underestimation of the baroclinic components. Since we only look for the order of 
TABLE 1. Summary of Mooring Positions, Launch Dates, Observation Periods, and Depths

\begin{tabular}{|c|c|c|c|c|c|}
\hline & Latitude North & Longitude West & Launch Date & Period, hours & Depth, m \\
\hline \multicolumn{6}{|c|}{ Iberian Basin } \\
\hline 203-1 & $38^{\circ} 00^{\prime}$ & $16^{\circ} 54^{\prime}$ & Dec. 8, 1977 & 3658 & 5550 \\
\hline $230-1$ & $40^{\circ} 31^{\prime}$ & $17^{\circ} 19^{\prime}$ & May 12,1978 & 5966 & 5310 \\
\hline \multicolumn{6}{|c|}{ Canary Basin } \\
\hline $264-1 *$ & $33^{\circ}$ & $22^{\circ}$ & April 1, 1980 & 4783 & 5285 \\
\hline $276-1 *$ & $33^{\circ}$ & $22^{\circ}$ & Oct. 17,1980 & 6785 & 5285 \\
\hline $276-2^{*}$ & $33^{\circ}$ & $22^{\circ}$ & July 28, 1981 & 5217 & 5285 \\
\hline $276-3^{*}$ & $33^{\circ}$ & $22^{\circ}$ & May 5,1982 & 9785 & 5285 \\
\hline $276-4^{*}$ & $33^{\circ}$ & $22^{\circ}$ & April 19,1983 & 4383 & 5285 \\
\hline $276-5^{*}$ & $33^{\circ}$ & $22^{\circ}$ & Oct. 20,1983 & 8899 & 5285 \\
\hline $276-6^{*}$ & $33^{\circ}$ & $22^{\circ}$ & Oct. 26, 1984 & 6468 & 5285 \\
\hline $276-7^{*}$ & $33^{\circ}$ & $22^{\circ}$ & Nov. 17,1985 & 8351 & 5285 \\
\hline 276-8* & $33^{\circ}$ & $22^{\circ}$ & Nov. 1, 1986 & 8872 & 5285 \\
\hline $277-2$ & $34^{\circ} 48^{\prime}$ & $23^{\circ} 05^{\prime}$ & July 29, 1981 & 5291 & 5155 \\
\hline $278-1$ & $31^{\circ} 00^{\prime}$ & $20^{\circ} 30^{\prime}$ & July 25,1981 & 5256 & 4850 \\
\hline $303-1$ & $26^{\circ} 02^{\prime}$ & $17^{\circ} 59^{\prime}$ & Nov. 12,1984 & 7889 & 3430 \\
\hline $304-1$ & $25^{\circ} 32^{\prime}$ & $17^{\circ} 03^{\prime}$ & Nov. 11, 1984 & 7919 & 3200 \\
\hline $307-1$ & $22^{\circ} 56^{\prime}$ & $20^{\circ} 30^{\prime}$ & Oct. 8, 1985 & 9467 & 4146 \\
\hline $308-1$ & $21^{\circ} 59^{\prime}$ & $22^{\circ} 02^{\prime}$ & Oct. 9,1985 & 9494 & 4572 \\
\hline $309-1$ & $19^{\circ} 02^{\prime}$ & $22^{\circ} 00^{\prime}$ & Oct. 11, 1985 & 9682 & 3460 \\
\hline $311-1$ & $36^{\circ} 02^{\prime}$ & $18^{\circ} 01^{\prime}$ & Dec. 2,1985 & 7951 & 5420 \\
\hline $313-1$ & $20^{\circ} 30^{\prime}$ & $23^{\circ} 37^{\prime}$ & Nov. 13, 1986 & 8894 & 4540 \\
\hline $414-1$ & $21^{\circ} 56^{\prime}$ & $25^{\circ} 14^{\prime}$ & Nov. 12,1986 & 8888 & 5143 \\
\hline $316-1$ & $30^{\circ} 00^{\prime}$ & $24^{\circ} 20^{\prime}$ & Nov. 8,1987 & 10432 & 5300 \\
\hline $317-1$ & $28^{\circ} 00^{\prime}$ & $25^{\circ} 38^{\prime}$ & Nov. 9, 1987 & 10434 & 5000 \\
\hline
\end{tabular}

*KIEL 276.

magnitude in the ratios of the four components at this point, this procedure appears acceptable. The results are presented in Figure 9.

In deep water the ratio between the components $M_{2}, S_{2}$, $K_{1}$ and $O_{1}$ is one order of magnitude each. At main thermocline levels, $K_{1}$ and $O_{1}$ and the rms error have similar magnitudes. Since the contribution of diurnal components is only $1 \%$ or less of the contribution by the semidiurnal components, and because errors are relatively large for the diurnal components in the upper ocean, we will restrict the analysis to the semidiurnal components $\mathrm{M}_{2}$ and $\mathrm{S}_{2}$ in the following discussion.

\section{Separation of Barotropic aNd Baroclinic TIDES}

The barotropic tide corresponds to a depth-independent current related to a long surface wave without friction. A simple method for separating baroclinic and barotropic components is provided by vertical averaging of the Fourier components as determined above. The average represents the barotropic component, and the residual represents the sum of the baroclinic components. In the case of only a few measurement levels the average may only provide a crude approximation of the barotropic component [Schott, 1977].

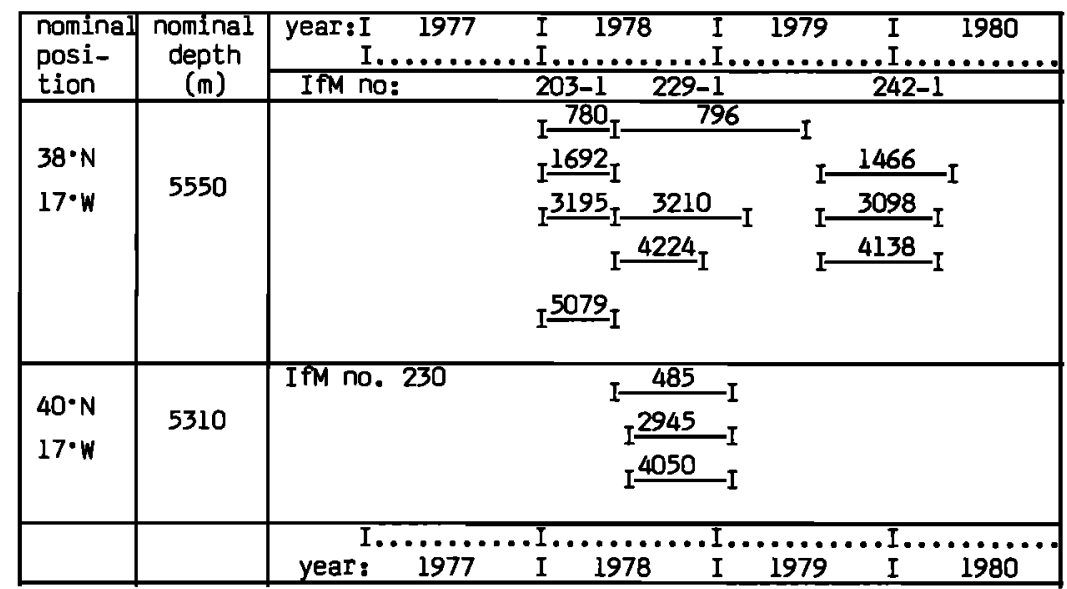

Fig. 3. Summary of current meter time series at individual depth levels in the Iberian Basin. 


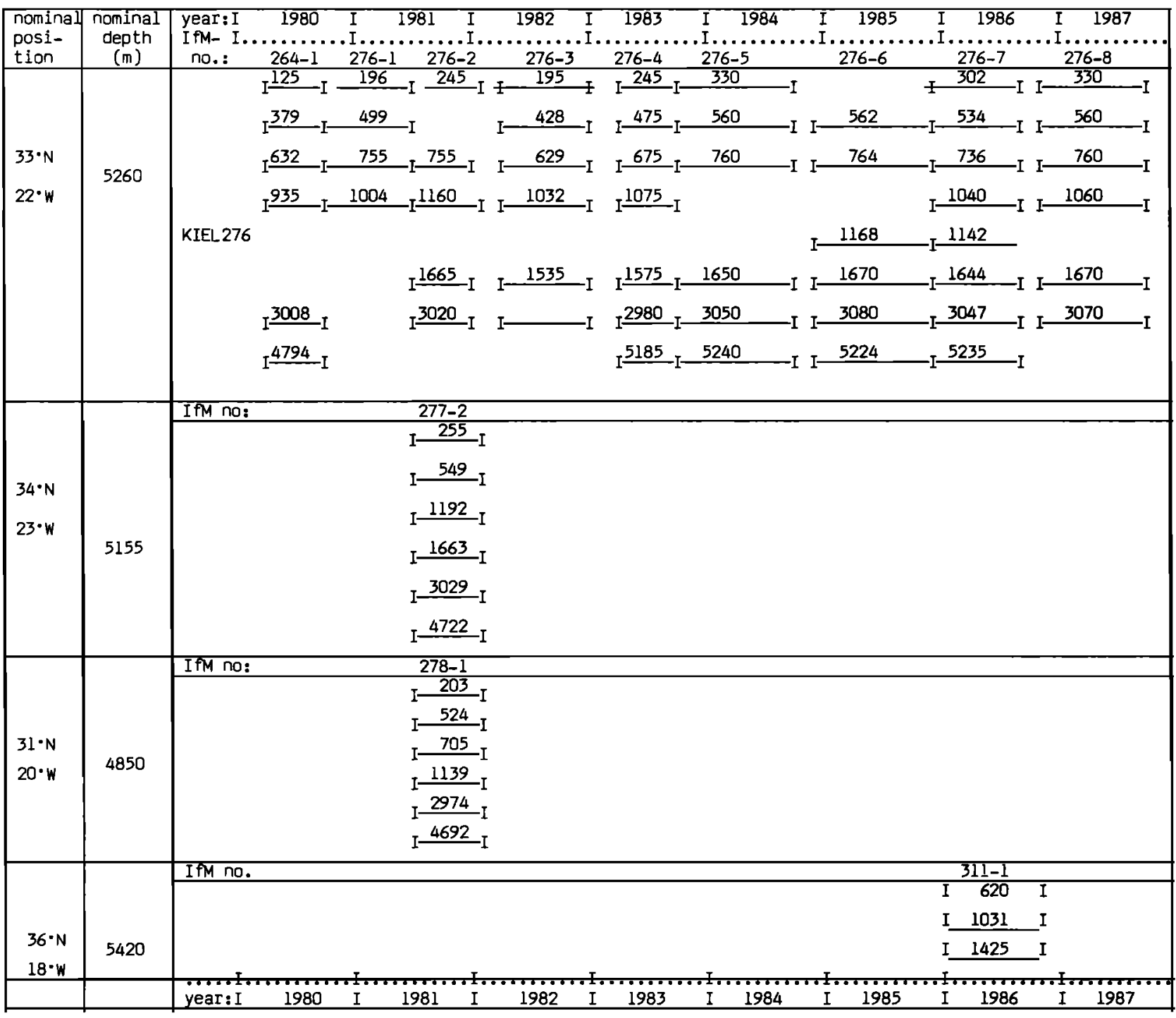

Fig. 4. Summary of current meter time series at individual depth levels in the northern Canary Basin.

We therefore prefer the method of fitting the data to dynamical mode components. With the usual assumptions for a linear internal wave field in an ocean at rest [e.g., LeBlond and Mysak, 1978] the vertical velocity amplitude $W_{n}$ of the dynamical mode of order $n$ is given by

$$
\frac{d^{2} W_{n}}{d z^{2}}+\frac{N^{2}-\sigma^{2}}{\sigma^{2}-f^{2}} k_{n}^{2} W_{n}=0
$$

where $z$ is the vertical coordinate, $N$ is the Brunt-Väisälä frequency, $\sigma$ is the wave frequency, $f$ is the inertial frequency, and $k_{n}$ is the horizontal wave number for mode $n$. With rigid surface and bottom conditions the horizontal velocities are obtained from the continuity equation

$$
\begin{aligned}
& u(z)=-\frac{\kappa \sigma+i \eta f}{\rho\left(\sigma^{2}+f^{2}\right)} p(z) \\
& v(z)=-\frac{\eta \sigma-i \kappa f}{\rho\left(\kappa^{2}+f^{2}\right)} p(z)
\end{aligned}
$$

where

$$
p(z)=-\frac{i \rho\left(\sigma^{2}-f^{2}\right)}{\sigma\left(\kappa^{2}+\eta^{2}\right)} \frac{d W_{n}}{d z}
$$

$u$ and $v$ are horizontal velocity components, $i$ is the imaginary unit $(-1)^{1 / 2}$, and $\kappa$ and $\eta$ are horizontal wave numbers, $\rho$ is density, and $p$ is pressure. Horizontal velocities are thus proportional to $d W_{n} / d z$. With $N^{2}$ given by the vertical density profiles from mean temperature and salinity at the locations of the moorings, the eigenfunctions $W_{n}$ and their vertical derivatives $d W_{n} / d z$ can be determined. The data can then be fitted to a sum of the $d W_{n} / d z$, either by assuming constant modal amplitude and phase for each component or by permitting slow (compared with tidal period) temporal variations of amplitude and phase.

With a limited number of observational levels, the order $n$ cannot be increased to high numbers. If we assume only one mode direction each, we have to determine one amplitude, phase, and direction per mode. Currents at each level comprise four variables, with amplitude and phase for two components. With the number $N$ of modes and the number $M$ of observational levels we obtain $4 M-3 N$ as the number 


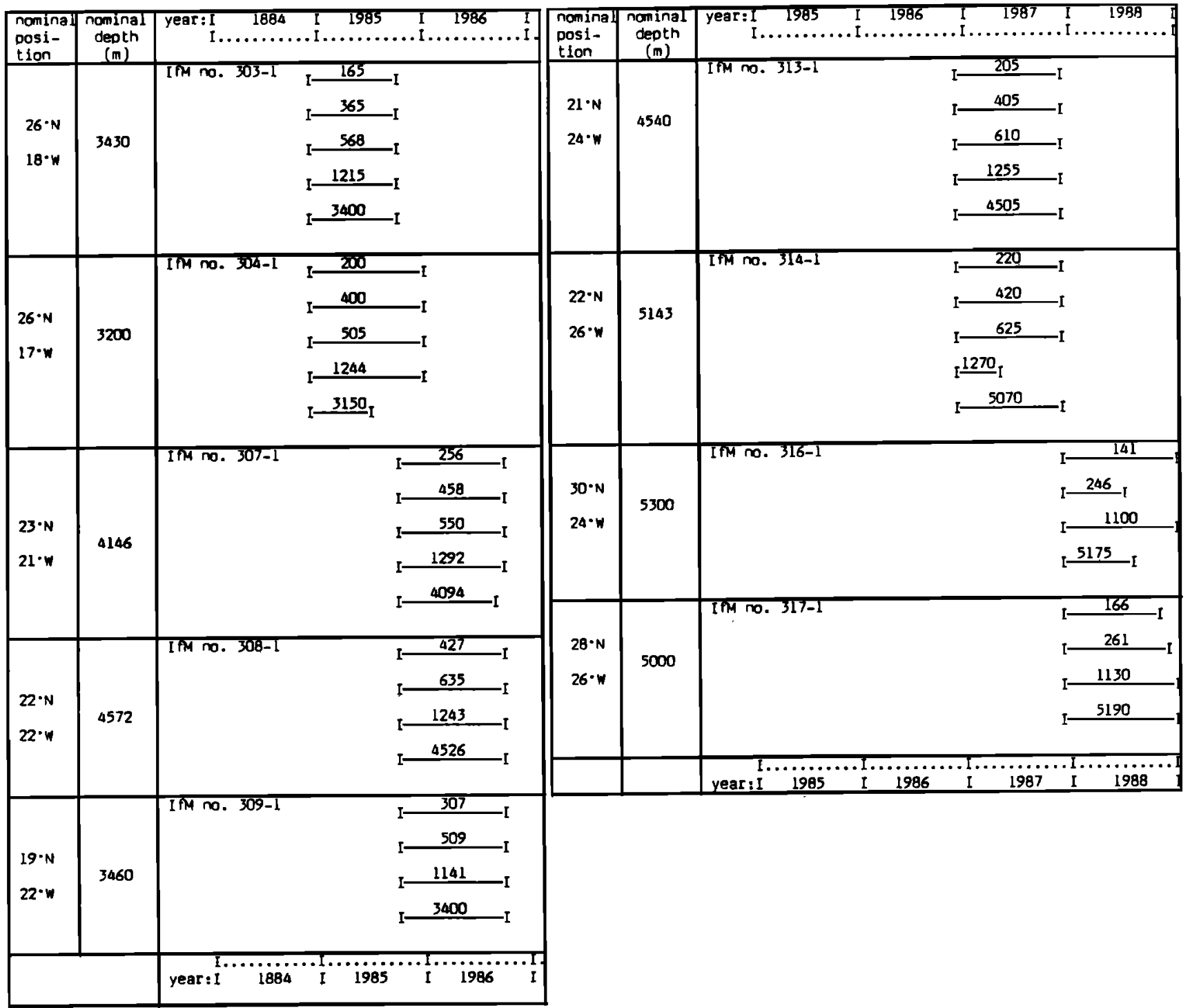

Fig. 5. Summary of current meter time series at individual depths levels in the central and southern Canary Basin.

of degrees of freedom. From an ensemble of 13 approximately 1-year records we determined the rms error when fitting first by mode 0 , then by modes 0 and 1 , and finally by modes 0,1 , and 2 . The normalized error only increased from 0.20 to 0.23 in this sequence. We considered this acceptable and therefore chose $N=3$, with the exception of moorings 230-1 and 311-1 where $N=2$ was selected because of less favorable instrument coverage (see Figures 3 and 4). This resulted in a minimum of six degrees of freedom.

Our analysis included the following steps:

Constant dynamical modes. This method was earlier used by Dick and Siedler [1985] with a subset of the present data for a study of barotropic tides in the area. Our results are consistent with their findings, and therefore we will not discuss the method in any detail.

Time-varying modes. In this case the data are fitted for each time step. All the following discussion will be based on this time-varying mode analysis. An example of the resulting time series for the barotropic and the first- and second-order baroclinic modes is presented in Figure 10, indicating the short time scales of internal wave events.

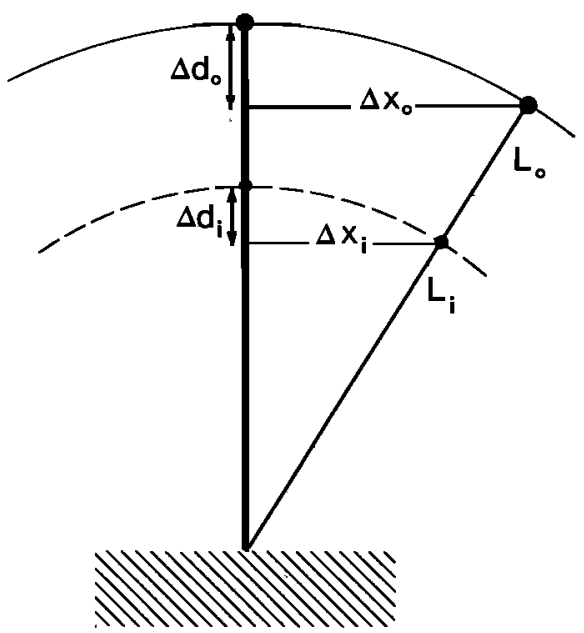

Fig. 6. Schematic mooring deflection due to current drag: $\Delta d_{0}$, $\Delta d_{i}$ are vertical displacement of instruments $o$ and $i, \Delta x_{o}, \Delta x_{i}$ are corresponding horizontal displacements; and $L_{o}, L_{i}$ are corresponding anchor distances. 

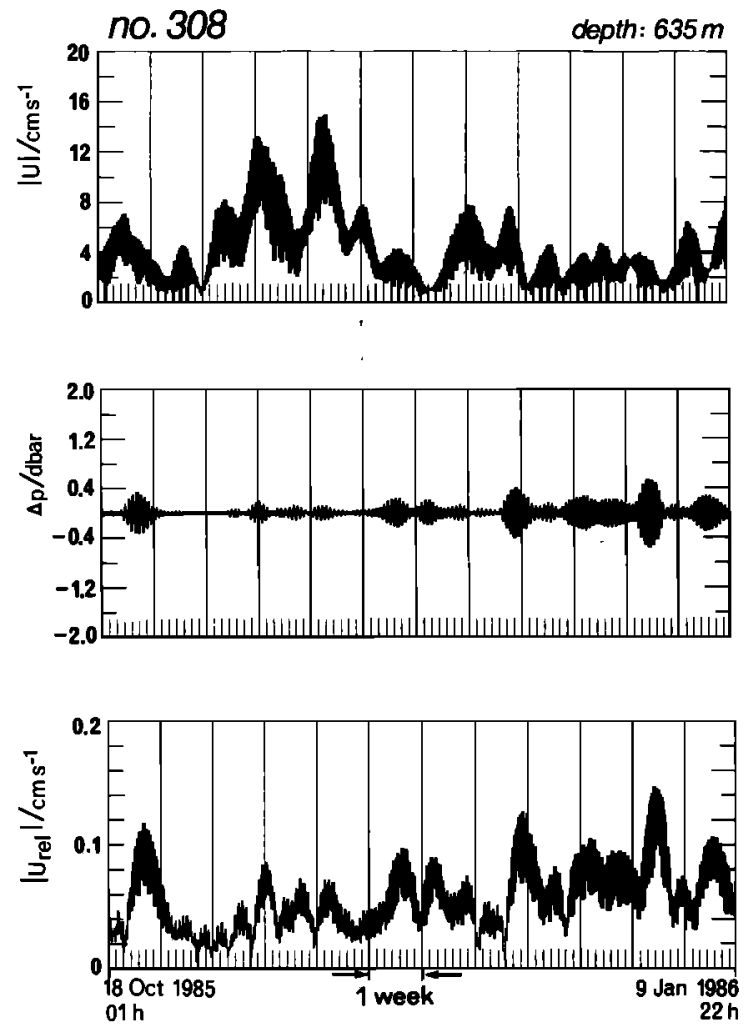

Fig. 7. Example of typical relative speeds due to drag-induced mooring line deflection: (top) observed speeds, (middle) vertical displacements, and (bottom) calculated relative speeds (note the change in scale between top and bottom plots).
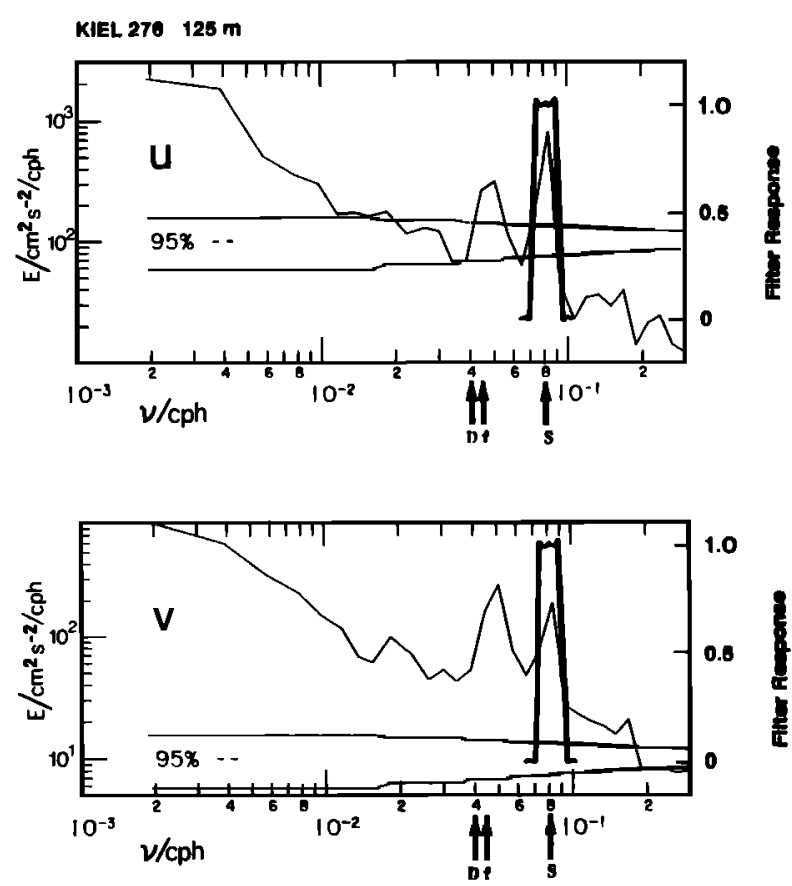

Fig. 8. Energy density $(E)$ spectra of east $(u)$ and north $(v)$ components from mooring KIEL276, period 264-1, and band pass filter response. The following periods are indicated on the frequency ( $\nu$ ) scale: D, diurnal; $f$, inertial; and $S$, semi-diurnal.

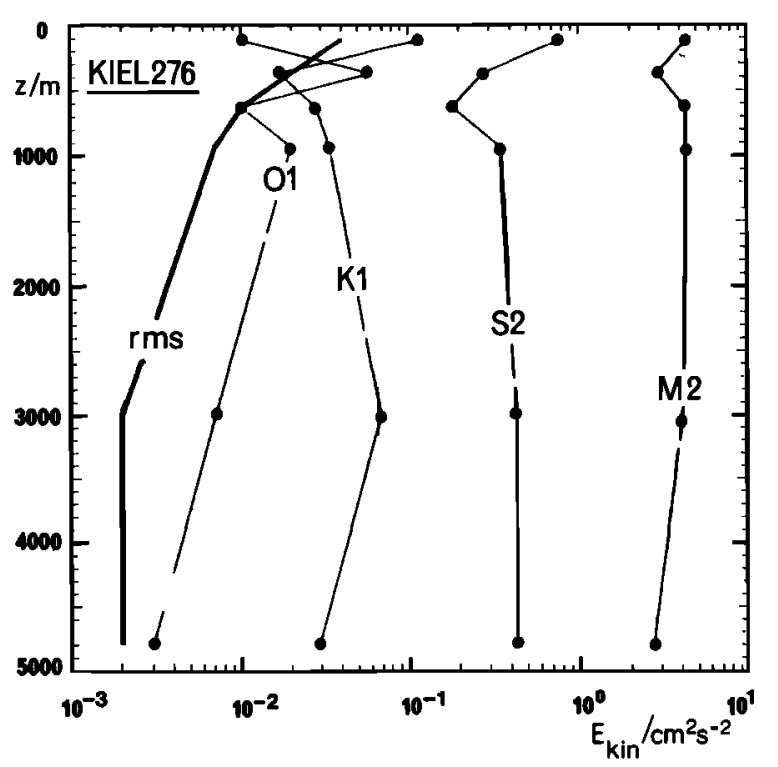

Fig. 9. Horizontal kinetic energy of semidiurnal $\left(\mathrm{M}_{2}, \mathrm{~S}_{2}\right)$ and diurnal $\left(\mathrm{K}_{1}, \mathrm{O}_{1}\right)$ tidal components obtained by Fourier analysis of a 1-year time series at mooring KIEL276 (see Figure 1). The average rms error for the four components, dominated by the error of the largest component, is presented on the left (note the logarithmic scale on the abscissa).
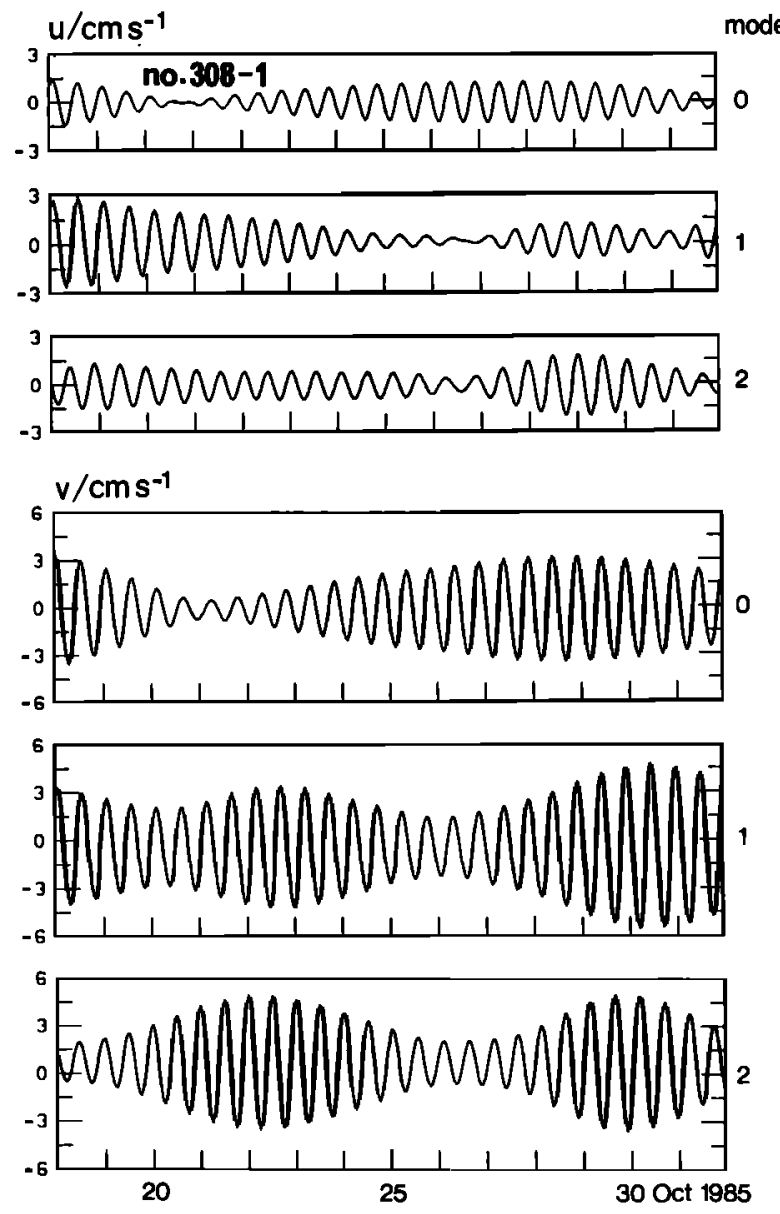

Fig. 10. Time series of barotropic and first- and second-order baroclinic $(n=1,2)$ modes at mooring $308-1$, where $u / v$ are east and north components of currents. 


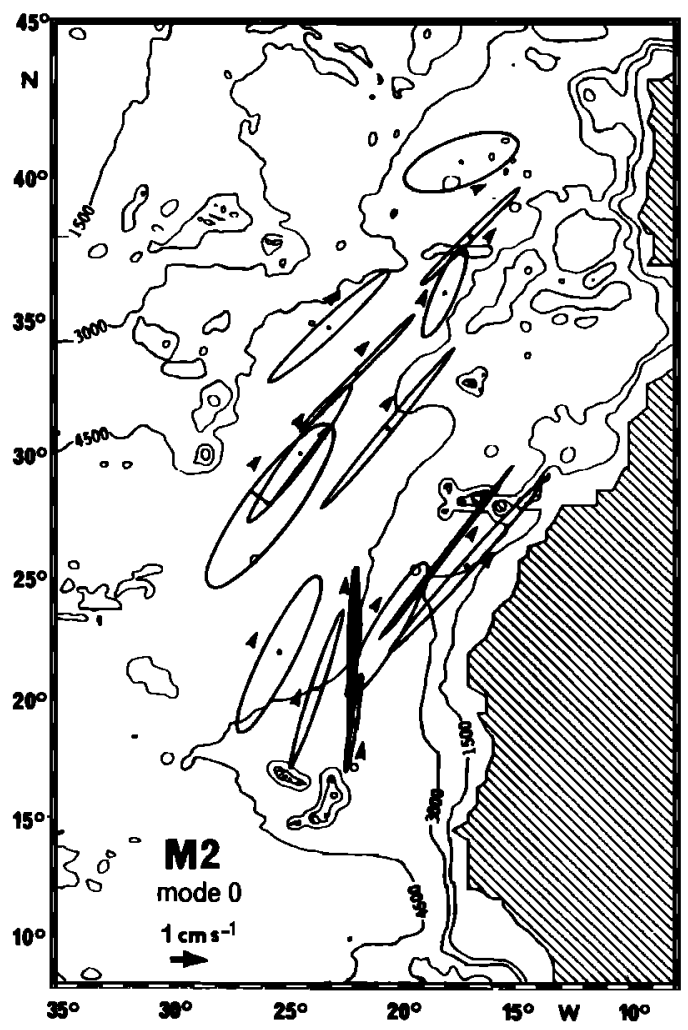

Fig. 11. Current ellipses for barotropic $M_{2}$ tide from this study. Rotational direction is indicated by arrow.

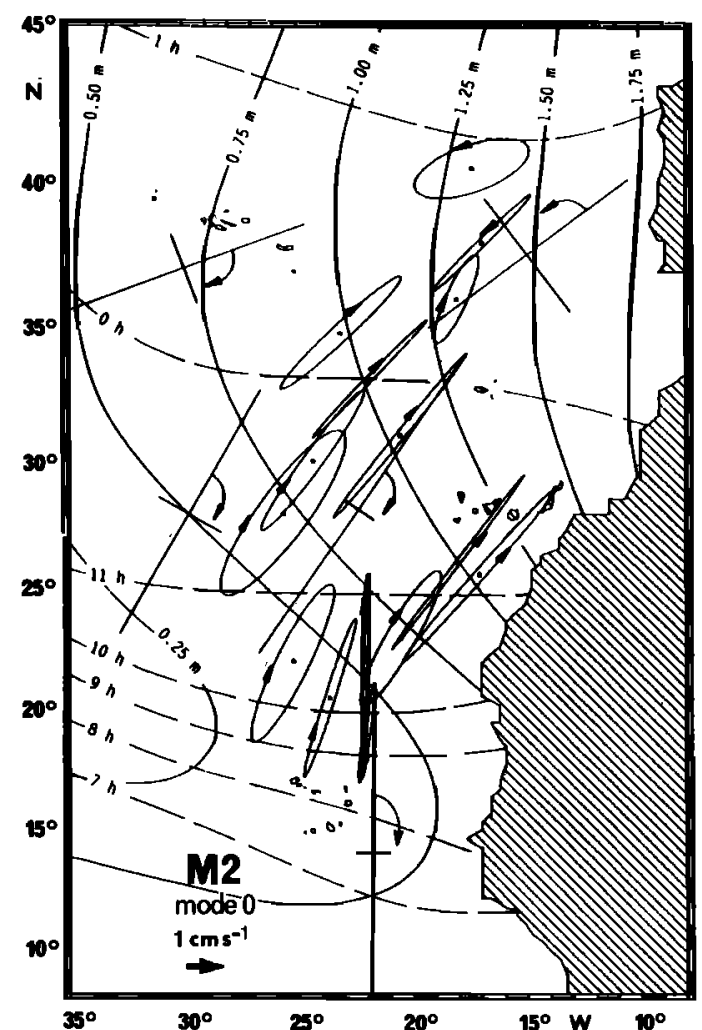

Fig. 13. Current ellipses for barotropic $M_{2}$ tide from this study superimposed on model results from Accad and Pekeris [1969]. Model ellipse axes (crosses) and cotidal (dashed) and corange (solid) lines from the model are presented. Rotational direction is given by arrow at ellipse or cross.

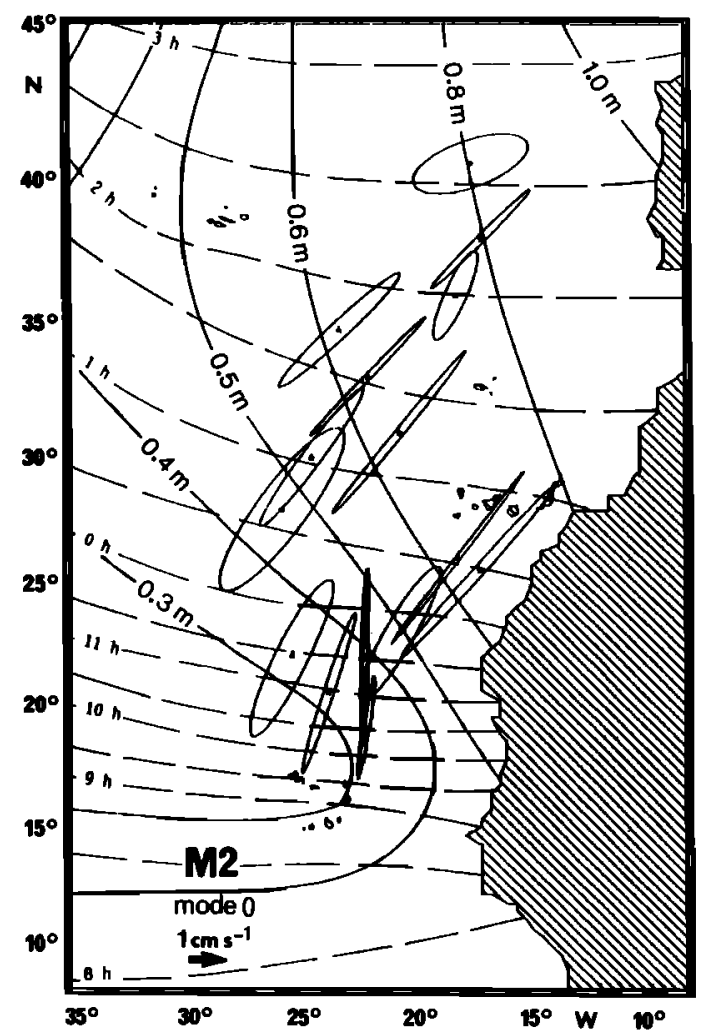

Fig. 14. Current ellipses for barotropic $M_{2}$ tide from this study superimposed on model results from Schwiderski [1979]. Cotidal (dashed) and corange (solid) lines from the model are indicated.
Fig. 12. Current ellipses for barotropic $S_{2}$ tide from this study. Rotational direction is indicated by arrow.

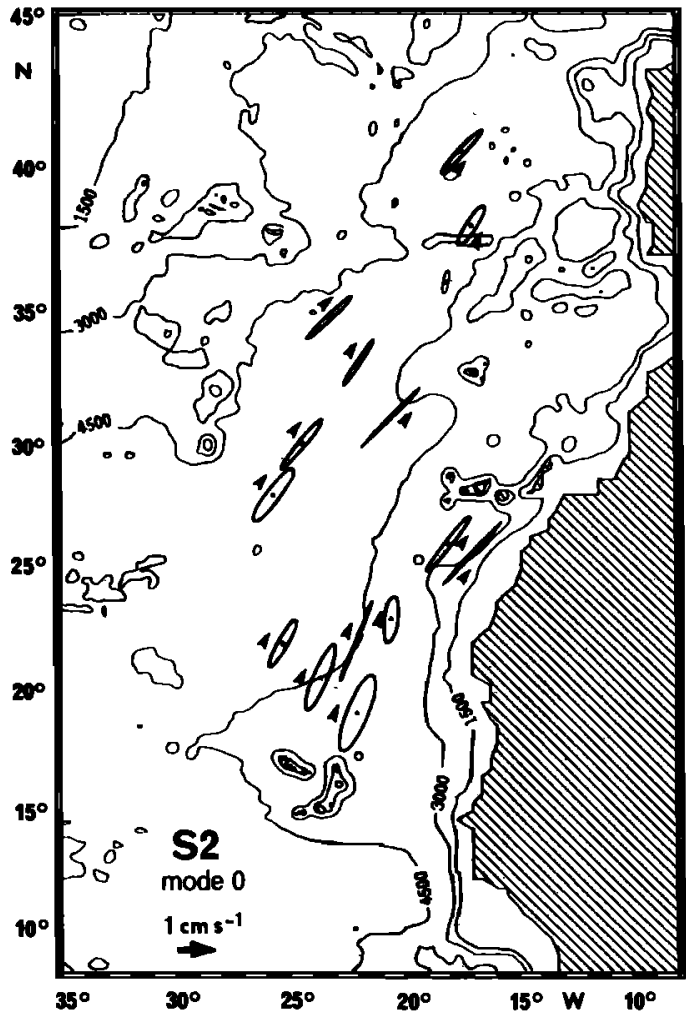



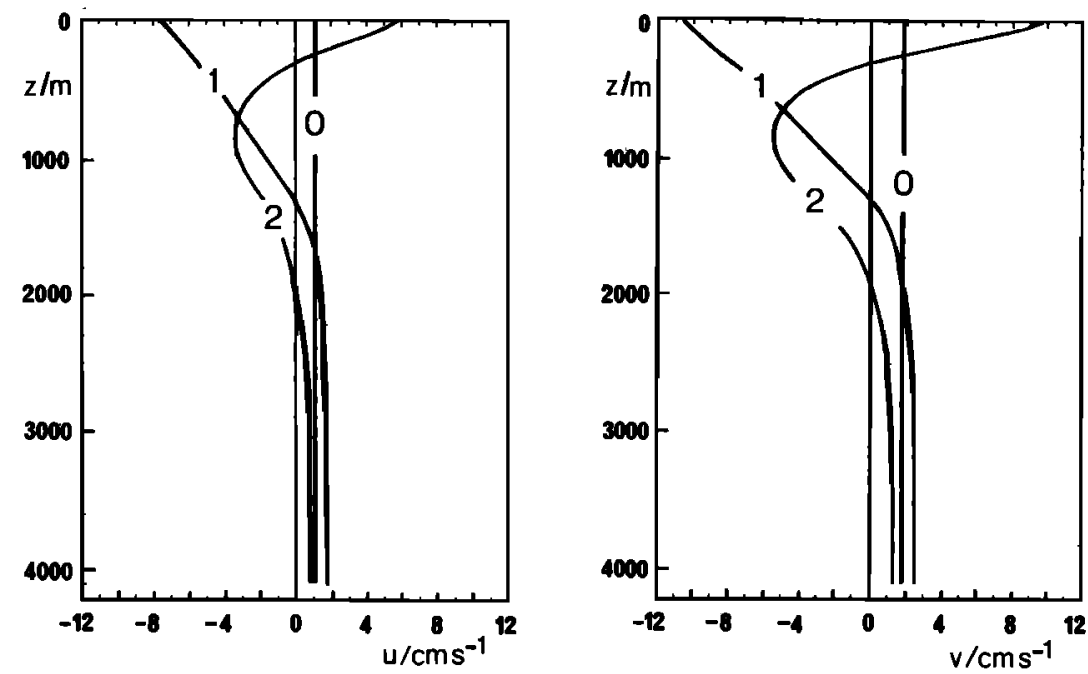

Fig. 15. Normal modes of order 0,1 , and 2 for east $(u)$ and north $(v)$ components of velocity for $\mathbf{M}_{2}$ tide at mooring 307 (see Figure 1).

Currents of mode 0 . These were determined at a selected level for a subset of moorings for direct comparisons with barotropic currents.

Vector variance time series for the different modes. This provides insight into temporal changes of internal tidal energy.

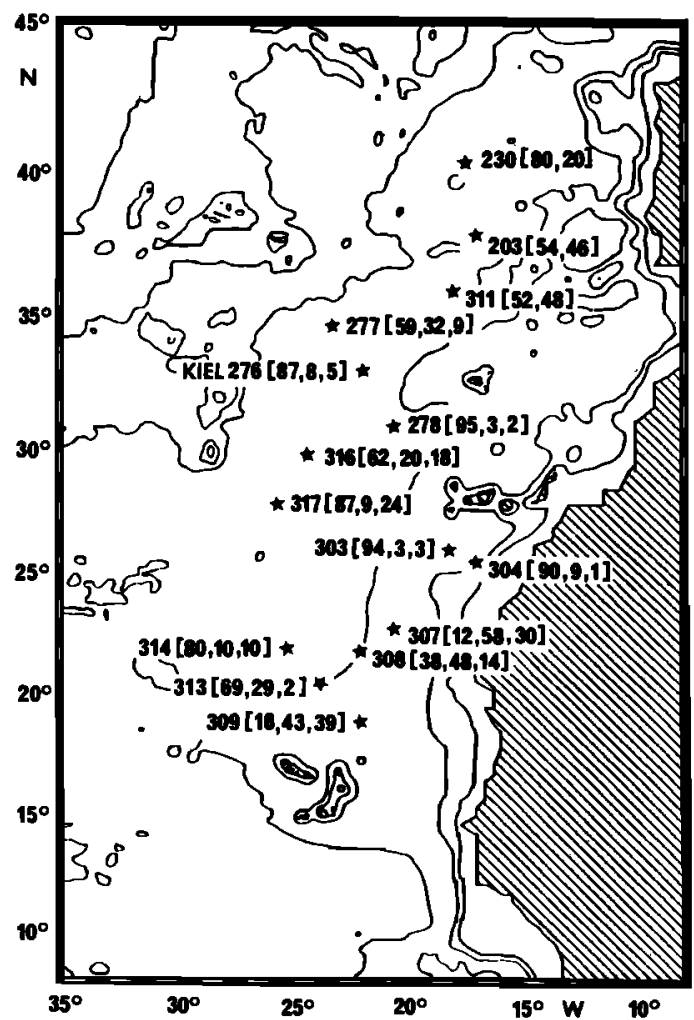

Fig. 16. Partition of $M_{2}$ tidal energy on modes 0,1 , and 2 at the different mooring sites. The numbers indicate: mooring number [percent energy of mode 0 , percent energy of mode 1 , percent energy of mode 2]. If only two numbers are given in the brackets, they refer to modes 0 and 1 , with mode 2 neglected.
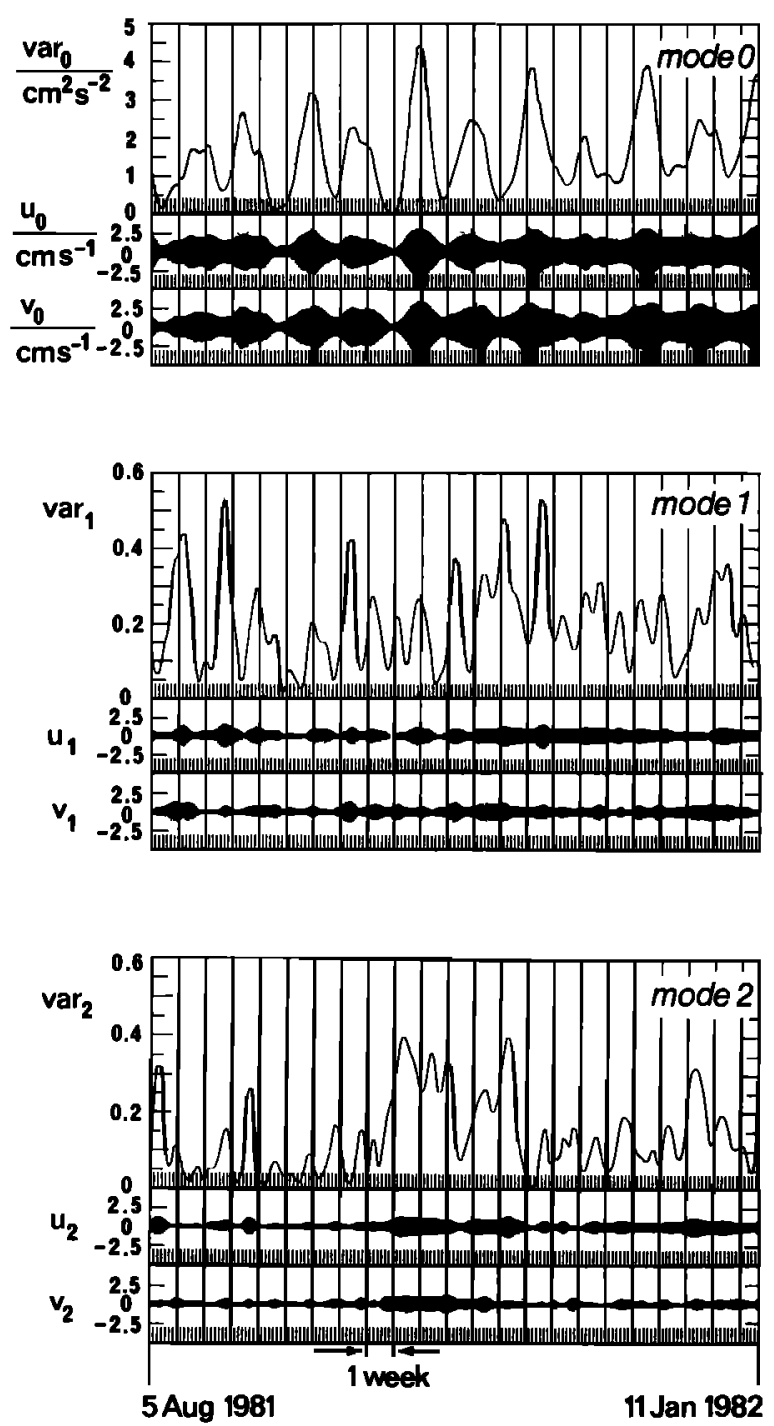

Fig. 17. Examples of time series of variance $\left(\operatorname{var}_{n}\right)$ and east $\left(u_{n}\right)$ and north $\left(v_{n}\right)$ velocity components for modes $n=0,1,2$ at site KIEL276 (see Figure 1). 

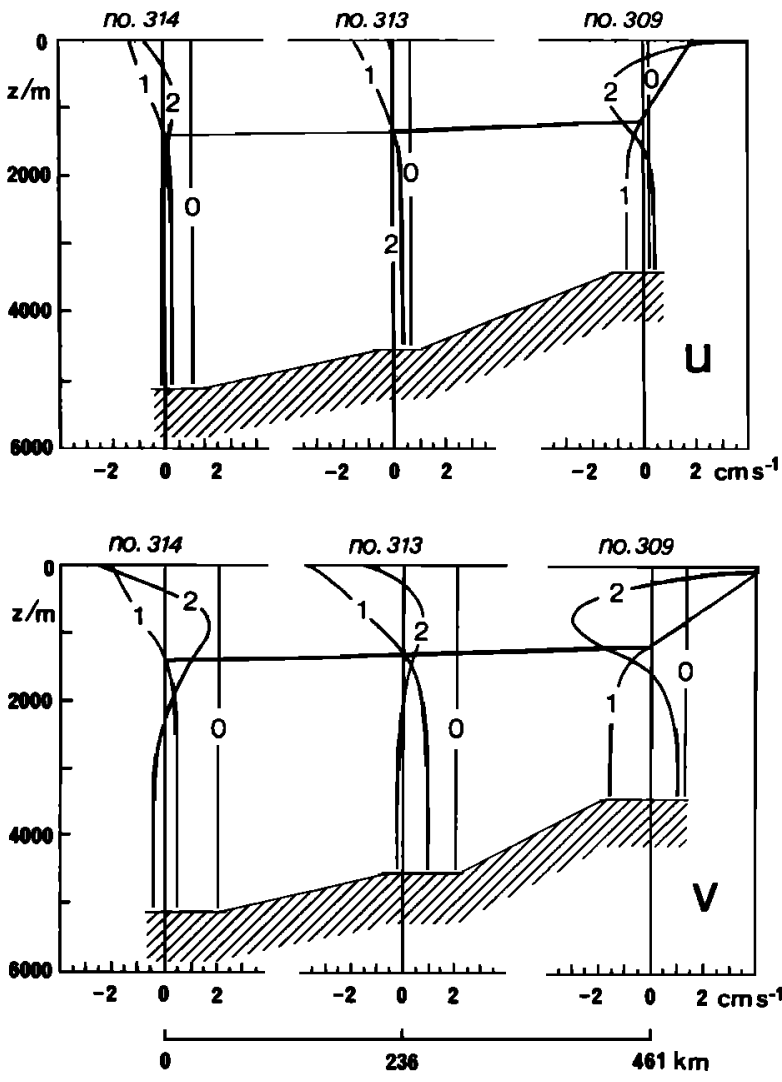

Fig. 18. Normal modes of order 0,1 , and 2 for east $(u)$ and north (v) velocity components of $M_{2}$ tide at the three sites 314,313 , and 309 on the Cape Verde Rise (see Figure 1).
Energy-preserving presentation of spectra. Such a spectra form is well suited to describing spatial changes of modal partition in the small-scale array near the Cape Verde Islands.

\section{BAROTROPIC TIDES}

Ellipse parameters were calculated from the Fourier coefficients of the barotropic tides. In the case of the multiyear records at KIEL276, the mean values were obtained by averaging the coefficients for 1-year series. The tidal ellipses for $M_{2}$ and $S_{2}$ are presented in Figures 11 and 12. The major axes of the ellipses are directed southwest-northeast in the deep basins and parallel to the continental slope at the basin boundaries. The magnitude of the $\mathbf{M}_{2}$ major axis is typically larger by a factor of 3 than the $S_{2}$ major axis.

We want to compare these observations with earlier model results. In Figure 13 we have superimposed our $\mathrm{M}_{2}$ ellipses and the cotidal and corange lines and tidal ellipse axes obtained by the model of Accad and Pekeris [1969]. In a frictionless ocean we expect the major ellipse axis to be oriented normal to cotidal lines. Some deviation from this direction is expected, since friction was included in the model. The ellipse orientations of the model and our observational results can be considered consistent. This is, however, not the case with respect to the magnitudes. The major axes from the model are typically twice the major axes from the observational results. It has been suggested that neglecting terms due to the solid Earth elasticity is the cause for exceedingly large magnitudes in the model of Accad and Pekeris [1969].

In Figure 14 our $M_{2}$ ellipses are superimposed on the cotidal and corange lines resulting from Schwiderski's [1979] no. 314
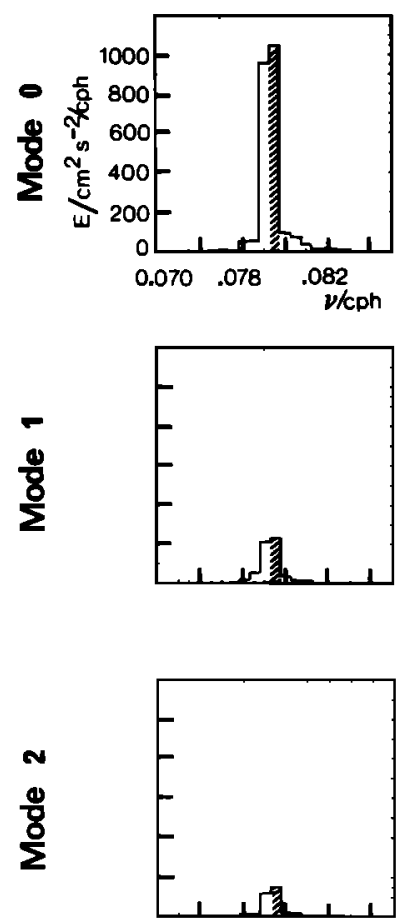

no. 313
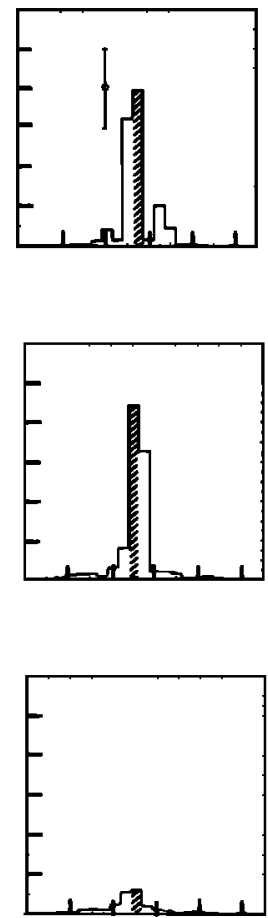

no. 309
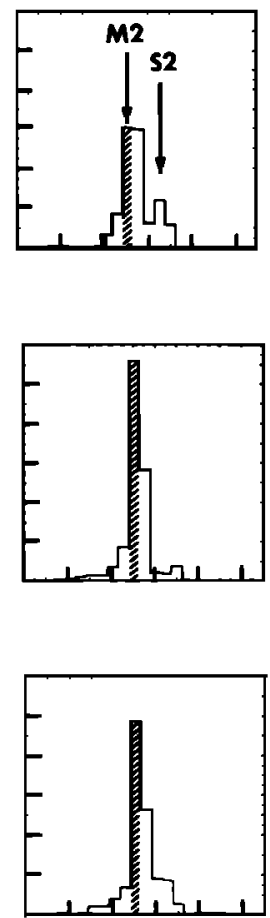

Fig. 19. Spectra in energy-preserving form for modal components 0,1 , and 2 at the three sites 314,313 , and 309 on the Cape Verde Rise (see Figure 1). The maximum energy bands are hatched. 

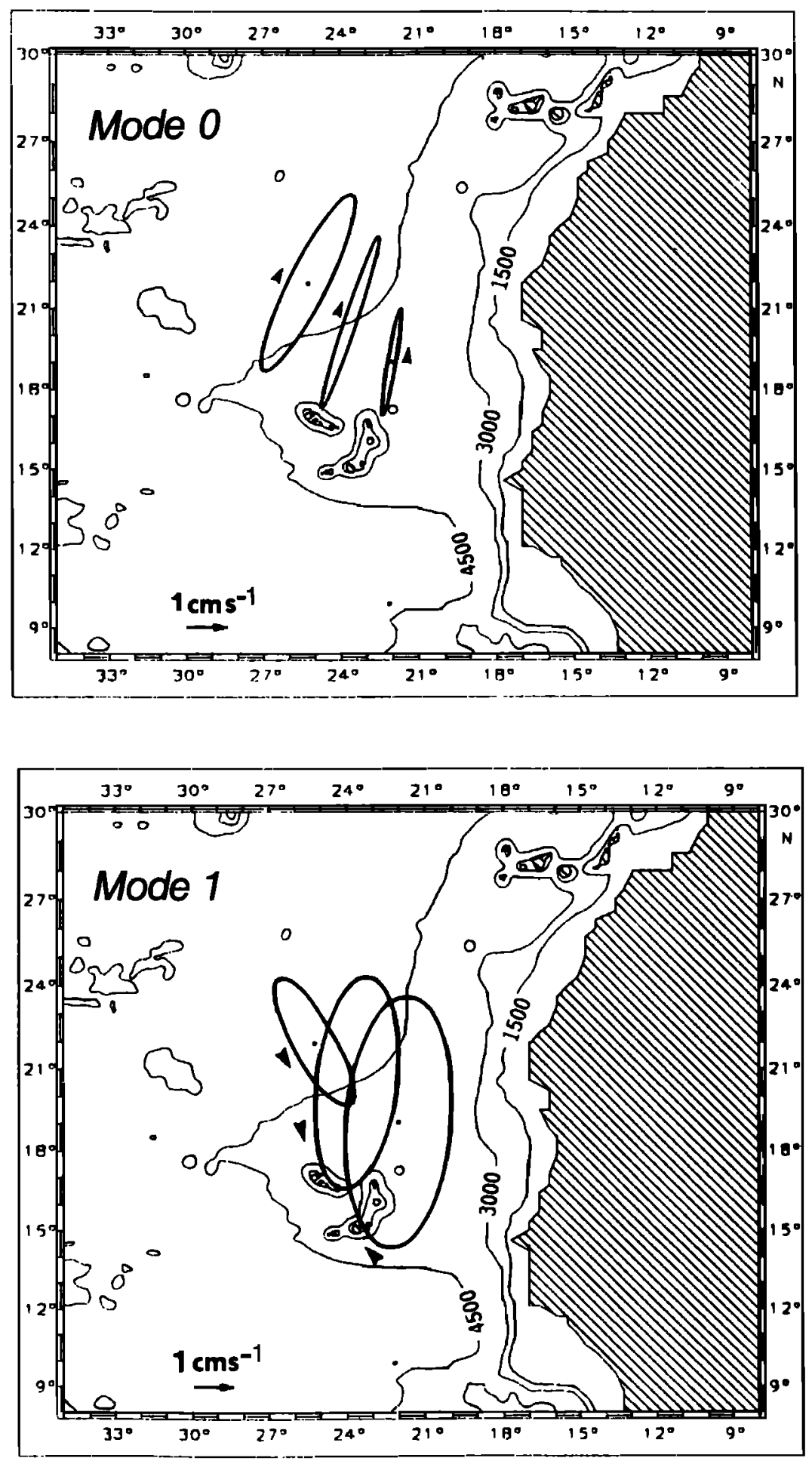

Fig. 20. Barotropic (mode 0 ) and first-order baroclinic (mode 1) current hodographs for $\mathbf{M}_{2}$ tide at the three sites 314 , 313, and 309 on the Cape Verde Rise (see Figure 1). Arrows indicate sense of rotation.

model, which takes account of solid Earth effects. Unfortunately, no tidal ellipses are available from the model. The overall pattern is similar to the Accad and Pekeris [1969] results, but the magnitudes are not. If we compare corange line distances in both model results, we find an approximate factor of 2 in the water level change, corresponding to a reduction in tidal ellipse axis length by this factor in this second model. Our observational results on $\mathbf{M}_{2}$ barotropic tidal amplitudes are thus in good agreement with the model of Schwiderski [1979] in this region.

\section{Baroclinic Tides}

We will now turn to the baroclinic tides, their regional distributions, and the partition of energy on barotropic and 
low-order baroclinic modes. A typical distribution of dynamical modes at a continental slope site on $4146 \mathrm{~m}$ depth near the Cape Verde Plateau is shown in Figure 15. The first mode $(n=1)$ has its zero crossing at approximately $1300 \mathrm{~m}$ depth, the second mode $(n=2)$ at 300 and $2000 \mathrm{~m}$. The maximum of tidal currents was observed near $500 \mathrm{~m}$ in this case because of similar direction of the two baroclinic modes. When comparing the total kinetic energies of the three modal constituents, we find a dominance of the first mode (58\%) and only a minor contribution of the barotropic mode (12\%). In their study of tides in the upwelling region close to our observational area Huthnance and Baines (1982) also found that the majority of baroclinic variability was represented by the first mode.

Figure 16 summarizes the partition of energy at the various sites of this study. In the deep basin we generally find the opposite situation to the case described above, with the barotropic tide dominant. The baroclinic contributions are usually larger over rough topography at the Mid-Atlantic Ridge and Azores Rise (moorings 277, 311, and 203), and they dominate at the three sites closest to the continental slope in the south $(309,308$, and 307). There are exceptions: At the deep-basin mooring 317 we find a fairly large secondorder baroclinic mode contribution, and a strong dominance of the barotropic mode is apparent at mooring 304 where the flow is apparently influenced by the topography downstream of the Canary archipelago. This latter position is characterized by exceptional flow properties also at lower frequencies [Müller and Siedler, 1991].

While the means will represent well the barotropic tidal energies because of long-term steady state conditions, this is not the case with the baroclinic tides. They will vary according to generation processes, source regions, and propagation. In order to recognize typical scales and magnitudes, time series of 12-hour means of variance and velocity components of the three modes have been calculated. An example from mooring KIEL276 is presented in Figure 17. As was already indicated in Figure 16, the barotropic energy is about $\mathbf{1 0}$ times larger here than the baroclinic energies. The variance of the barotropic tide is dominated by the regular 2-week spring-neap cycle. The typical time scales of the baroclinic components are shorter, of the order of 5 days. We find no indication of a correspondence between the spring-neap cycle and baroclinic tidal events here which could be expected in the case of internal tide generation due to barotropic tides near the shelf break [Lee, 1961; Gargett, 1970; Halpern, 1971; Baines, 1982; Sherwin, 1988]. Obviously, this site is too far away from the possible generation area to find such a correspondence.

A special data set is provided by the cross-slope array north of the Cape Verde Islands (moorings 309, 313, and 314; see Figure 1). The structure of modes 0,1 , and 2 for that array is presented in Figure 18, and spectral energies and tidal ellipses are displayed in Figures 19 and 20, respectively. We find systematic changes in amplitudes from the deepest to the shallowest site. The barotropic signal decreases toward shallower depths, and both the first- and second-order baroclinic modes increase in this direction. In the case of standing surface waves in a basin we will expect a narrowing of tidal ellipses when approaching the boundary. This is the case here. But we also find a steady decrease in the main axis amplitude which might be interpreted as an indication of energy transfer from barotropic to baroclinic tides at the
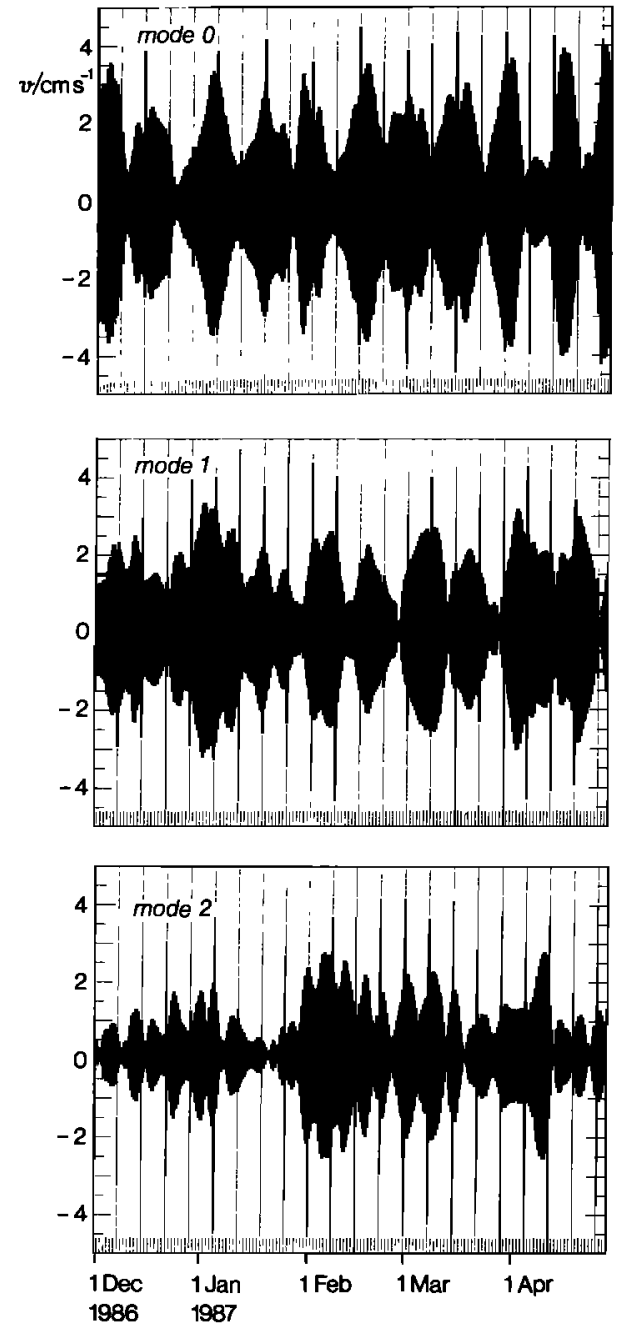

Fig. 21. North component modes 0,1 , and 2 from partial record at mooring 313 . The long-term trend was removed.

continental slope and shelf. This is supported by the decrease in baroclinic tidal energy from shallower to deeper water recognized in Figures 19 and 20 . The steady decrease is consistent with baroclinic tide generation on the shelf and slope and energy losses during the propagation of the internal tides to the deeper ocean.

Further evidence for this generation process is provided in Figures 21 and 22 . We selected north velocity components of mooring 313 (See Figure 1) in the Cape Verde Rise array, providing stronger signals than the east components as obvious from Figure 20. After the removal of the long-term trend, we obtain the modal magnitudes presented in Figure 21. The 2-week spring-neap cycle is seen as a strong signal in the barotropic mode, and a similar periodicity is recognized in the series of the first-order baroclinic mode but not in the second-order baroclinic mode. The corresponding spectra are displayed in Figure 22. The peaks at 2-week periods are seen in the mode 0 and mode 1 spectra, but not in the mode 2 spectra. We conclude that baroclinic tides are generated on the continental slope and/or shelf in this region by the barotropic tide, with the resultant spring-neap cycle apparent in the baroclinic signals. 

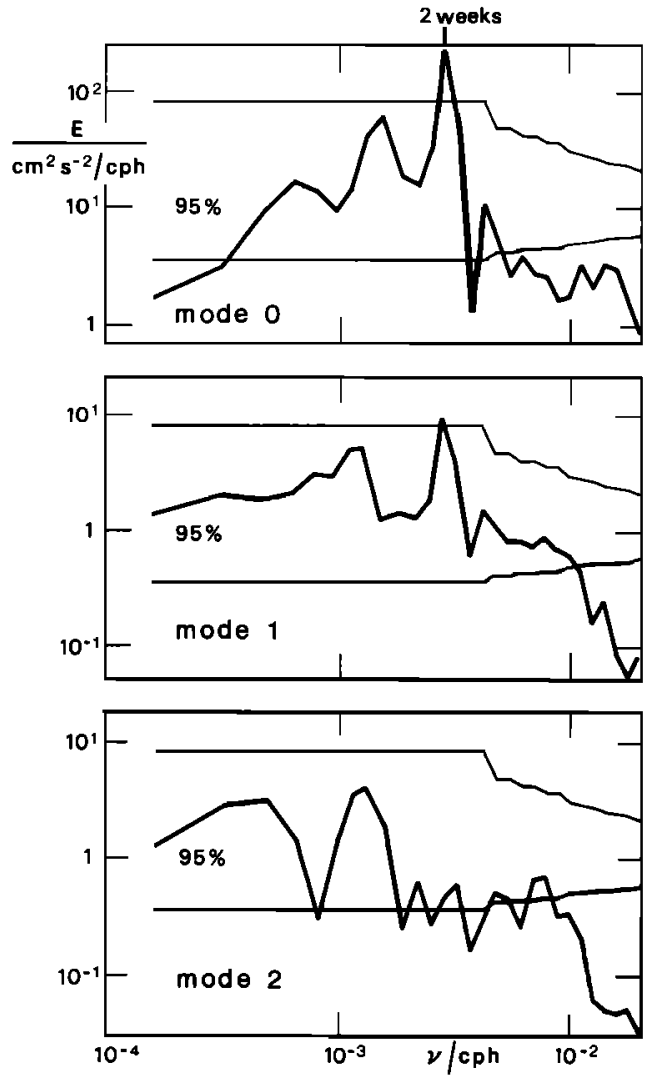

Fig. 22. Energy density spectra of modes 0,1 , and 2 from full record at mooring 313, corresponding to the time series in Figure 21.

\section{Conclusions}

The observational data confirm the results on barotropic tides obtained from the Schwiderski [1980] model in this region. According to earlier authors, the tidal signals are usually dominated by the barotropic tides [see Wunsch, 1975], but there exist exceptions [Gould and McKee, 1973; Huthnance and Baines, 1982]. In our study we find that a distinction has to be made in this respect depending on location. At the deep-basin moorings we observe the expected dominance of the barotropic mode, with 60 to $80 \%$ of tidal energy, but this is not usually the case near the continental slope or at the Cape Verde Rise, nor over rough topography at the Mid-Atlantic Ridge or Azores Rise. A single exception to this behavior is provided by one mooring in the area downstream of the Canary archipelago.

Lower levels of (horizontal) barotropic tidal kinetic energy can be expected near the basin boundaries and are observed in the case of long standing surface waves. The shoreward enhancement of the baroclinic tide is consistent with the usually accepted explanation of internal tide generation by surface tide forcing of isopycnal surfaces over topographic features. All our moorings are seaward of the critical slope [Wunsch, 1975; Baines, 1982] where the internal tide source region is expected, which occurs at the continental margin just off the shelf. In the records of the moorings closest to the slope in the south we also find a correlation of internal tidal energy with the spring-neap cycle, a result expected for the topographic generation of the baroclinic waves [Hecht and Hughes, 1971]. The ratio of first- to second-order baroclinic mode energies is always larger than 1 , but the results from the southern Canary Basin indicate an increasing contribution of the second-order mode when approaching the generation region near the shelf.

Acknowledgments. We have benefited much from discussions with T. J. Müller, and we would also like to acknowledge the helpful comments received from R. Käse and J. Kielmann. Observations for this study were funded by the Deutsche Forschungsgemeinschaft (SFB 133).

\section{REFERENCES}

Accad, Y., and C. L. Pekeris, Solution of Laplace's equation for the $\mathrm{M}_{2}$ tide in the world oceans, Philos. Trans. R. Soc. London, Ser. $A, 265,413-436,1969$.

Accad, Y., and C. L. Pekeris, Solution of the tidal equations for the $\mathrm{M}_{2}$ and $\mathrm{S}_{2}$ tides in the world oceans from a knowledge of the tidal potential alone, Philos. Trans. R. Soc. London, Ser. A, 290, 235-266, 1978.

Baines, P. G., On internal tide generation models, Deep Sea Res., $29,307-338,1982$.

Cartwright, D., A. Edden, R. Spencer, and J. Vassie, The tides of the northeastern Atlantic Ocean, Philos. Trans. R. Soc. London, Ser. $A, 298,396-439,1980$.

Defant, A., Die Gezeiten und interne Gezeitenwellen des Atlantisches Oceans, Wiss. Ergeb. Dtsch. Atl. Exped. Meteor 19251927, 7(1), 318 pp., 1932.

Defant, A., Physical Oceanography, vol. II, 590 pp., Pergamon, New York, 1960.

Dick, G., and G. Siedler, Barotropic tides in the northeast Atlantic inferred from moored current meter data, Dtsch. Hydrogr. Z., 38(1), 7-22, 1985.

Dickson, R. R., World Ocean Circulation Experiment, Flow statistics from long-term current-meter moorings, the global data-set in January 1989, Rep. WCRP-30 (WMO/TD-No. 337), 35 pp., 711 tables, World Meteorol. Organ., Geneva, 1989.

Dietrich, G., Die Schwingungssysteme der halb- und eintägigen Tiden in den Ozeanen, Veroeff. Inst. Meereskd. Univ. Berlin, N.F.(A)41, 1-68, 1944.

Gargett, A., Internal waves in the Strait of Georgia, Ph.D. thesis, 113 pp., Univ. of B. C., Vancouver, Canada, 1970.

Godin G., The Analysis of Tides, 264 pp., Liverpool University Press, Liverpool, England, 1972.

Gordon, R. L., Tidal interactions in a region of large bottom slope near northwest Africa during JOINT-1, Deep Sea Res., 26, 199-210, 1979.

Gould, W. J., and W. D. McKee, Vertical structure of semidiurnal tidal currents in the Bay of Biscay, Nature, 244, 88-91, 1973.

Halpern, D., Semidiurnal internal tides in Massachusetts Bay, $J$. Mar. Res., 29(2), 116-132, 1971.

Hecht, A., and P. Hughes, Observations of temperature fluctuations in the upper layers of the Bay of Biscay, Deep Sea Res., 18, 663-684, 1971.

Hendershott, M., Ocean tides, Eos Trans. AGU, 54, 76-86, 1973.

Huthnance, J. M., Large tidal currents near Bear Island and related tidal energy losses from the North Atlantic, Deep Sea Res., 28, $51-70,1981$.

Huthnance, J. M., and P. G. Baines, Tidal currents in the northwest African upwelling region, Deep Sea Res., 29, 285-306, 1982.

Käse, R. H., and G. Siedler, Internal wave kinematics in the upper tropical Atlantic, Deep Sea Res., Part A, 26, 227-232, 1979.

Krauss, W., Methoden und Ergebnisse der theoretischen Ozeanographie, vol. 2, Interne Wellen, 248 pp., Borntraeger, Stuttgart, Germany, 1966.

LeBlond, P., and L. Mysak, Waves in the Ocean, 602 pp., Elsevier, New York, 1978.

Lee, O., Observations of internal waves in shallow water, Limnol. Oceanogr., 6(3), 312-321, 1961.

Levine, M., C. Paulson, M. Briscoe, R. Weller, and H. Peters, Internal waves in JASIN, Philos. Trans. R. Soc. London, Ser. A, 308, 389-405, 1983.

Magaard, L., and W. D. McKee, Semi-diurnal tidal currents at site D, Deep Sea Res., 20, 997-1010, 1973.

Meincke, J., Der Einfluss der Grossen Meteorbank auf Schichtung 
und Zirkulation der ozeanischen Deckschicht, Meteor Forschungsergeb., Reihe A, 9, 67-94, 1971.

Meincke, J., G. Siedler, and W. Zenk, Some current observation near the continental slope of Portugal, Meteor Forschungsergeb., Reihe A, 16, 15-22, 1975.

MODE Group, The Mid-Ocean Dynamics Experiment, Deep Sea Res., 25, 859-910, 1978.

Müller, T. J., and G. Siedler, Multi-year current time series in the eastern North Atlantic Ocean, J. Mar. Res., in press, 1991.

Munk W., and D. Cartwright, Tidal spectroscopy and prediction, Philos. Trans. R. Soc. London, Ser. A, 259, 533-581, 1966.

Regal, R., and C. Wunsch, $\mathbf{M}_{2}$ tidal currents in the western North Atlantic, Deep Sea Res., 20, 493-502, 1973.

Roberts J., Internal gravity waves in the ocean, 274 pp., Marcel Dekker, New York, 1975.

Saunders P., Benthic observations on the Madeira Abyssal Plain: Currents and dispersion, J. Phys. Oceanogr., 13, 1416-1429, 1983.

Schmitz, W. J., Jr., J. F. Price, and P. L. Richardson, Recent moored current meter and SOFAR float observations in the eastern Atlantic near $32^{\circ} \mathrm{N}, J$. Mar. Res., 46, 301-319, 1988.

Schott, F., On the energetics of baroclinic tides in the North Atlantic, Ann. Geophys., 33, 41-62, 1977.

Schwiderski, E. W., Global ocean tides, II, The semidiurnal principal lunar tide $\left(\mathrm{M}_{2}\right)$, Atlas of tidal charts and maps, NSWC Tech.
Rep. 79-414, 11 pp., Nav. Surf. Weapons Cent., Dahlgren, Va., 1979.

Schwiderski, E. W., On charting global ocean tides, Rev. Geophys., I8(1), 243-268, 1980

Sherwin, T., Analysis of an internal tide observed on the Malin shelf, north of Ireland, J. Phys. Oceanogr., 18, 1035-1050, 1988.

Torgrimson, G. M., and B. M. Hickey, Barotropic and baroclinic tides over the continental slope and shelf off Oregon, J. Phys. Oceanogr., 9, 945-961, 1979.

Weisberg, R. H., D. Halpern, T. Y. Tang, and S. M. Hwang, $\mathbf{M}_{2}$ tidal currents in the eastern equatorial Pacific Ocean, J. Geophys. Res., 92(C4), 3821-3826, 1987.

Wunsch, C., Internal tides in the ocean, Rev. Geophys., 13, 167182,1975 .

Wunsch, C., and R. Hendry, Array measurements of the bottom boundary layer and the internal wave field on the continental slope, Geophys. Fluid Dyn., 4, 101-145, 1972.

U. Paul and G. Siedler, Institut furr Meereskunde an der Universität Kiel, Düsternbrooker Weg 20, D-2300 Kiel, Federal Republic of Germany.

(Received March 22, 1991; accepted June 5, 1991.) 